\title{
Differential Genomic Approach to Explore Phylogenetic Link
}

Mandakini Singla ${ }^{1}$, Sharma VL ${ }^{1}$, Sobti RC $^{2}$ and Anathbandhu Chaudhuri ${ }^{3^{*}}$

${ }^{1}$ Department of Zoology, Panjab University, Chandigarh-160014, India

${ }^{2}$ BBAU, Lucknow - 226025, India

${ }^{3}$ Department of Natural Sciences, Stillman College, Tuscaloosa-35401, USA

\begin{abstract}
Different approaches are in progress to study phylogenetic relatedness and divergence among organisms. Genomic study is the most effective method for resolving phylogenetic relationships. Multiple genes are preferred over single gene sequence analysis and whole genome sequences are nowadays is the best nucleotide sequence-based approach to identify and classify the taxonomically complex group of organisms to deal with several phylogenetic issues. Various bioinformatics tools are providing valuable information to study significant evolutionary relationships such as next generation sequencing, proteomics etc. DNA barcoding technology is also recently used skill to study phylogeny and identify the morphologically ambiguous species by amplifying a small fragment of Cytochrome $\mathrm{C}$ Oxidase Subunit I (COI). We recently reported multiple gene phylogenies of Indian termites resulting in incongruent results. However, whole genome analysis will provide a significant outcome to resolve the diverse observations studied in these species.
\end{abstract}

Keywords: Phylogeny; Whole genome; DNA barcoding; Termites

\section{Editorial}

Molecular phylogenies based on single genes often resulted in divergent conclusions and use of multiple gene series was proposed to end these contradictory results. Single gene phylogenies usually produce dissonant results lacking significant support in relation to statistics and produce very small data to resolve phylogenetic relatedness. In contrast, the use of multiple gene analysis and different tree reconstruction methods leads to well-resolved statistically significant differential approach. To reduce differential results, the data containing minimal nonphylogenetic signals should be used to take maximum advantage of phylogenomics [1].

Whole genome analysis of living organisms using mitochondrial and chloroplast genomes, is best preferred method commonly used to infer phylogeny rather than sequencing single genes. Different attempts to study genome evolution based on binary character encoding, distance methods using software, maximum parsimony, maximum likelihood, method of invariants, Bayesian analysis, statistical approach and mutations related to divergence were observed. Also it has been proposed that genome molecular data should be combined with fossil records to improve the phylogenetic inference of organisms [2].

DNA barcoding technology is an another method based on the partial fragments (about $650 \mathrm{bp}$ ) mitochondrial cytochrome $\mathrm{c}$ oxidase subunit I (COI) gene with the use of a single set of primers for a highly conserved gene that is present in all taxa to make molecular identification and phylogeny analysis of commonly identified species an easy process [3].

Very recently we examined the phylogenetic position of various species of Indian termites belonging to order Isoptera in relation to other termite species of different geographical locations based on 12 SrRNA, COI, COII, ND1 genes [4-7]. The observations by the use of multiple genes contributed differential results and demonstrated the usefulness of the whole genome analysis in further phylogenetic and evolutionary inspection of termites. Also, phylogeny can help in validating the morphological identity which is convenient to recognize unidentified species. This can further be confirmed by using DNA barcoding skill.

\section{Acknowledgement}

We thank UGC, Government of India for supporting termites study. Also, we would like to thank Mr. Sourav Garg, Department of Materials Science Engineering, University of Alabama, Tuscaloosa to edit the manuscript.

\section{References}

1. Olivier J, Henner B, Frédéric D, Hervé P (2006) Phylogenomics: the beginning of incongruence? Trends Genet 22: 225-231.

2. Pyron RA (2015) Post-molecular systematics and the future of phylogenetics Trends in Ecology and Evolution 30: 384-389.

3. Casiraghi M, Labra M, Ferri E, Galimberti A, De Mattia F (2010) DNA barcoding a six-question tour to improve user's awareness about the method. Briefings in Bioinformatics 11: 440-453.

4. Singla M, Sharma VL, Sobti RC, Sodhi M, Kumari M (2013) Genetic relationship among Indian termites based on DNA sequence of mitochondrial $12 \mathrm{~S}$ ribosomal RNA gene. Int J Evol 2: 1.

5. Sharma VL, Singla M, Sobti RC (2013) Phylogenetic position of Indian termites (Isoptera: Termitidae) with their respective genera inferred from DNA sequence analysis of the mitochondrial cytochrome oxidase gene subunit I compared to subunit II. Molecular and Cellular Biochemistry. Mol Cell Biochem 384:39-45.

6. Singla M, Goyal N, Sobti, RC, Sharma VL (2015) Estimating molecular phylogeny of some Indian termites combining partial $\mathrm{COI}$ sequences. Journal of Entomology and Zoology Studies 3: 213-218.

7. Goyal N, Singla M, Sharma VL (2015) Intraspecific systematics of genus Odontotermes inferred from analysis of the mitochondrial ND1 gene. Journal of Insect Science 28: 274-278.

*Corresponding author: Anathbandhu Chaudhuri, Assistant Professor Biology, Stillman College, Tuscaloosa-35401, USA, Tel: (205) 366-8914; E-mail: achaudhuri@stillman.edu

Received March 28, 2016; Accepted April 01, 2016; Published April 06, 2016

Citation: Singla M, Sharma VL, Sobti RC, Chaudhuri A (2016) Differential Genomic Approach to Explore Phylogenetic Link. J Phylogen Evolution Biol 4: e118. doi:10.4172/2329-9002.1000e118

Copyright: ( 2016 Singla M, et al. This is an open-access article distributed under the terms of the Creative Commons Attribution License, which permits unrestricted use, distribution, and reproduction in any medium, provided the original author and source are credited. 